\title{
O Ginásio Osvaldo Cruz de Dourados nas páginas do jornal estudantil $A B C$ : ensino secundário no sul de Mato Grosso nos anos 1960
}

\section{The School Osvaldo Cruz de Dourados in the pages of studant newspaper ABC: high school in the south of Mato Grosso in the 1960s}

\section{La Escuela Osvaldo Cruz de Dourados en las páginas del periódico estudiantil ABC: enseñanza secundaria en el sur de Mato Grosso en los años 1960}

Kênia Hilda Moreira ${ }^{1}$

Eglem Oliveira Passone-Rodrigues ${ }^{1}$

DOI: http://dx.doi.org/10.20435/serie-estudos.v22i46.999

\begin{abstract}
Resumo: Analisam-se os discursos em torno da criação e consolidação da instituição escolar Osvaldo Cruz de Dourados, em Dourados, sul de Mato Grosso, durante a década de 1960, veiculadas nas páginas do jornal estudantil O ABC (ou ABC Literário), que circulou em 1961, 1962 e 1968, tendo sido criado e mantido pelos alunos secundaristas da referida instituição. Questionam-se as representações estabelecidas sobre a instituição no periódico em questão, considerando os referenciais teórico-metodológicos sobre história das instituições, o impresso como fonte de pesquisa para a história da educação e o conceito de representação. Conclui-se que o periódico em análise, enquanto jornal estudantil, tem grande potencial de fonte e permitiu, com o auxílio de outros documentos, contribuir para apresentar um itinerário de vida da referida instituição escolar.
\end{abstract}

Palavras-chave: história das instituições educativas; impresso pedagógico como fonte; sul de Mato Grosso.

\begin{abstract}
This article analize speeches around the creation and consolidation of the school Osvaldo Cruz de Dourados in Dourados, Mato Grosso do Sul, during the 1960s, aired in the pages of the student newspaper $O A B C$ (or $A B C$ Literário), have been created and maintained by high school students of the institution. This article question about the representations established on the School in the journal, considering the theoretical and methodological references on the history of institutions, printed as a research source for the history of education and the concept of representation. It is concluded that the school students'periodical in question, has great power potential and has, with the help of other documents, help provide an itinerary of life of that educational institution.
\end{abstract}

${ }^{1}$ Universidade Federal da Grande Dourados, Dourados, Mato Grosso do Sul, Brasil. 
Key words: history of educational institutions; pedagogical printed as source; south of Mato Grosso.

Resumen: Se analizan los discursos en torno a la creación y consolidación de la institución escolar Osvaldo Cruz de Dourados, en la ciudad de Dourados, ubicada al sur de Mato Grosso, durante la década de 1960, transmitidas en las páginas del periódico estudiantil El ABC (o ABC Literario), que circuló en 1961, 1962 y 1968, habiendo sido creados y mantenidos por los alumnos secundarios de dicha institución. Se cuestionan las representaciones establecidas sobre la institución en el periódico en cuestión, considerando los referenciales teórico-metodológicos sobre historia de las instituciones, el impreso como fuente de investigación para la historia de la educación y el concepto de representación. Se concluye que el periódico en análisis, como periódico estudiantil, tiene gran potencial de fuente y permitió, con el auxilio de otros documentos, contribuir a presentar un itinerario de vida de la referida institución escolar.

Palabras clave: historia de las instituciones educativas; imprenta pedagógica como fuente; sur de Mato Grosso.

\section{INTRODUÇÃO}

O Ginásio Osvaldo Cruz de Dourados - extensão do Colégio Osvaldo Cruz de Campo Grande 2 - que começou a funcionar em 1954, na cidade de Dourados, sul de Mato Grosso, atual Mato Grosso do Sul, é nosso objeto de pesquisa. Neste artigo, utilizamos como fonte, principalmente, o jornal estudantil $O A B C$, criado e mantido pelos alunos secundaristas ${ }^{3}$ dessa instituição, e que circulou nos anos de 1961, 1962 e 1968, o que justifica o recorte temporal na década de 1960. Trata-se de pesquisa inédita, considerando que a revisão de literatura constatou tratar-se de objetos inéditos, tanto o Ginásio quanto o jornal estudantil $O A B C^{4}$.

Com o objetivo de analisar os discursos impressos no referido jornal, de questionar sobre as representações sociais em torno do Ginásio Osvaldo Cruz de Dourados e evidenciar algumas práticas dos alunos secundaristas nos anos 1960, mobilizamos referenciais que lidam com o impresso como fonte de pesquisa para a história da educação e da história das instituições educativas para sustentar nossas inferências. De modo geral, ancoramo-nos nos princípios metodológicos da Nova História Cultural,

2 O Ginásio Osvaldo Cruz de Campo Grande elevou-se à categoria de Colégio em 1949, a partir do Decreto-Lei n. 4.244/1942, ampliando seu atendimento para os dois ciclos do ensino secundário.

${ }^{3}$ Entendemos ensino secundário como a etapa escolar posterior ao ensino primário, de caráter propedêutico ao ensino superior, seletivo no ingresso de estudantes (Zotti, 2005).

${ }^{4}$ Nenhuma pesquisa que abrangesse os objetos foi encontrada, o que já foi produzido sobre o colégio se refere à unidade sede em Campo Grande, como a dissertação de Rocha (2010) intitulada "O ensino secundário no sul do estado de Mato Grosso no contexto das reformas educacionais: o Ginásio Osvaldo Cruz (1927-1949)". 
que permitem a expansão documental, introduzindo o impresso como fonte e objeto de pesquisa e ampliando as noções de práticas e representações.

A revolução historiográfica estabelecida a partir da Escola dos Annales e da Nova História culminou, dentre outros fatores, na expansão documental como fonte de investigação, e o uso da imprensa começou a ser disseminado nos diversos campos de pesquisa, principalmente nos inseridos na perspectiva da Nova História Cultural, proporcionando o distanciamento "de um tempo em que a imprensa era considerada como fonte suspeita, a ser usada com cautela, pois apresentava problemas de credibilidade" (CRUZ; PEIXOTO, 2007, p. 254). No campo de pesquisa em história da educação, essa inserção também aconteceu, em especial, com os impressos pedagógicos.

Entre as pesquisas internacionais que utilizaram a imprensa periódica como fonte de pesquisa histórica, destacam-se os trabalhos de Maurits de Vroede, em 1987, que investigaram as revistas belgas dos séculos XIX e XX, Pierre Caspard, 1988, que elencou revistas francesas do século XVIII a princípios do século XX, Giorgio Chiosso, 1992, que destaca as revistas italianas da segunda metade do século XVIII, António Nóvoa, 1994, que toma a imprensa de educação e ensino portuguesa, nos séculos XIX e XX e os recentes trabalhos do espanhol Hernández Díaz (2013; 2015), que apresenta a imprensa pedagógica como patrimônio histórico educativo e o repertório analítico sobre o impresso pedagógico em Castilla y León, entre 1973 e 1936.

Denice Barbara Catani, Maria Helena Câmara Bastos, Marta Carvalho e seus orientandos respectivos impulsionaram os estudos em torno das revistas pedagógicas no Brasil. O interesse pelo impresso como fonte/objeto para a história da educação em nosso país ganha força a partir do final da década de 1980, e a proliferação e diversificação das pesquisas foram mais visíveis dos anos 1990 aos nossos dias, em especial, a partir da obra "História Cultural", de Roger Chartier.

Atentos na especificação das fontes, consideramos como "impressos" periódicos e revistas que têm como objetivo informar e criar opinião, construindo espaços sociais coletivos. Em outros termos, um instrumento de comunicação social que faz parte da vida cotidiana dos cidadãos e, desse modo, também espaço de presença de educação e seus problemas, além de permanente ação educativa (BICCAS, 2008). O "impresso pedagógico", foco deste artigo, é assim considerado, conforme Hernández Díaz (2013, p. 16), quando: "na sua sequência temporal mantém um critério de atenção e estudo expressamente interessando em assuntos que afetam os processos da educação, dentro da instituição escolar ou em outras, mas também 
educativas e formativas" ${ }^{\prime}$.

Sobre o estudo da imprensa pedagógica e/ou estudantil, Catani e Bastos (2002, p. 5), expõem que esse tipo de imprensa

[...] feita por professores para professores, feita para alunos e seus pares ou professores... contém e oferece muitas perspectivas para a compreensão da história da educação e do ensino. Sua análise possibilita avaliar as políticas das organizações, as preocupações sociais, os antagonismos e filiações ideológicas, as práticas educativas.

Uma vez que os impressos são portadores da palavra escrita, eles "cimentam as sociabilidades e prescrevem comportamentos, atravessam o foro privado e a praça pública, levam a crer, a fazer ou a imaginar (CHARTIER, 1990, p. 138). É nesse sentido que pretendemos analisar o jornal $O A B C$, em busca de discursos que criaram representações e práticas em torno do Ginásio Osvaldo Cruz de Dourados nos anos 1960, identificando como essa realidade social foi "construída, pensada, dada a ler" (CHARTIER, 1990, p. 17).

Como expõe Hernández Díaz (2013, p. 16), ao nos debruçarmos sobre os impressos pedagógicos, estamos diante de um mar de possíveis publicações educativas, um imenso espaço pedagógico, "que merece ser utilizado como instrumento de apoio e investigação pelo intérprete do passado educativo", que somos nós, historiadores da educação ${ }^{6}$.

Os 12 exemplares do jornal estudantil que compõem a fonte dessa investigação, disponíveis no Centro de Documentação Regional (CDR), da Universidade Federal da Grande Dourados (UFGD), são: n. 2, 6 e 7, equivalentes aos meses de maio, setembro e outubro de 1961; n. 8 a 10, correspondentes aos meses de março, abril e maio de 1962; e n. 1 ao 6, nos meses de março, abril, maio (com duas publicações: n. 3 e 4), agosto e setembro de 1968, ano em que o nome do periódico passa a ser ABC LITERÁRIO'.

\footnotetext{
${ }^{5}$ Tradução nossa. Versão original: "en su secuencia temporal mantiene un criterio de atención y estudio expresamente interesado en asuntos que afectan a los procesos de la educación, dentro de la institución escolar o en otras diferentes pero también educativas y formativas".

${ }^{6}$ Tradução nossa. Versão original: "que merece ser utilizado como instrumento de apoyo e investigación por el intérprete del pasado educativo".

${ }^{7}$ Apesar de não termos encontrado um exemplar do número 1, de 1961, a leitura do corpus elucida que ele data de abril de 1961. A mesma leitura indica que o jornal deixou de circular em 1962 e foi retomado em 1968, tendo sido organizado por diferentes grupos de estudantes do Colégio Osvaldo Cruz durante sua vigência.
} 
O Ginásio Osvaldo Cruz de Dourados nas páginas do jornal estudantil ABC: ensino secundário no sul de Mato Grosso nos anos 196

Independente da nomenclatura, se O ABC (1961-1962) ou ABC LITERÁRIO (1968), o periódico em questão sempre esteve veiculado aos alunos do Osvaldo Cruz de Dourados. Trata-se, portanto, de um impresso feito por estudantes secundaristas. O jornal $O A B C$ foi uma iniciativa dos alunos ligados ao Órgão do Grêmio Estudantil "Coelho Neto" e o ABC LITERÁRIO ao Grêmio Estudantil "Osvaldo Cruz". Quando nos referirmos ao jornal como $O A B C$, estamos tratando de ambas as publicações, tanto de $O A B C$ quanto do $A B C L I T E R A ́ R I O$, considerando tratar-se de uma continuidade, apesar da ruptura e da mudança de nome, como explica o editor do jornal em $1968^{8}$.

Tendo o jornal como fonte principal, pois como alerta Hernández Díaz, trata-se, sem dúvida, de um objeto de "grande importância para compreender que imagem se quer passar de dentro da instituição para fora" ${ }^{9}$, atentamo-nos para os referenciais da história das instituições e para o impresso como fonte para a história da educação, possível a partir da "atualidade dos discursos historiográficos no quadro educacional associada a uma renovação epistemológica, através da interdisciplinaridade e da multifatorialidde" conforme Magalhães (1996, p. 111), para quem

Compreender e explicar a existência histórica de uma instituição educativa é, sem deixar de integrá-la na realidade mais ampla que é o sistema educativo, contextualizá-la, implicando-a no quadro de evolução de uma comunidade e de uma região, é por fim sistematizar e (re)escrever-lhe o itinerário de vida na sua multidimensionalidade, conferindo um sentido histórico. (MAGALHÃES, 1996, p. 2).

Com o objetivo de contribuir para a história da instituição escolar Osvaldo Cruz de Dourados enquanto um "organismo vivo", e atentos às questões propostas por Magalhães (2004, p. 124), especialmente no que diz respeito à integração da instituição educativa ao contexto, considerando os processos históricos nacionais e

\footnotetext{
${ }^{8}$ O primeiro artigo da primeira edição de 1968 intitula-se "O ABC, 1961", escrito pelo diretor Doratildo Pereira, e conta a trajetória do Jornal desde 1961, os desdobramentos e rupturas, até o ressurgimento em 1968. O autor inicia fazendo menção ao mês de abril de 1961, quando o jornal O ABC iniciava sua caminhada, como um dos "primeiros jornais estudantis douradenses (talvez mesmo o primeiro em caracteres tipográficos)", e continua afirmando que, em pouco tempo, o jornal se tornou um "verdadeiro representante da classe estudantil. Vale dizer também que era o único que se mantinha, apesar das grandes dificuldades materiais que enfrentava". O autor conclui afirmando que, como tudo muda e passa, "Êsse jornalzinho também mudou, também passou. Morreu-lhe o corpo, o corpo, não a alma. Hoje, seis anos depois, como a fonte que seca e que volta a jorrar água límpida, voltamos a circular" (O ABC LITERÁRIO, 1968a, p. 1).

${ }^{9}$ Tradução nossa. Versão original: "gran interés para comprender qué imagen se quiere trasladar del establecimiento hacia el exterior".
} 
regionais que delinearam o ensino secundário no sul de Mato Grosso e atentos a necessidade de entrecruzar fontes diversas, isso nos levou, para além dos jornais estudantis $O A B C$, a buscar outras fontes.

Considerando que o acervo escolar do Osvaldo Cruz foi doado ao CDR no ano de 2015, mas ainda não foi catalogado, o que dificultou nossa busca nesse acervo, recorremos ao acervo pessoal de Elisabete Regina Lins de Laet, filha de José Pereira Lins, proprietário, diretor e professor no Osvaldo Cruz entre os anos de 1954 a 2000. Além de fotografias da instituição e uma entrevista do professor Lins (áudio), feita pela rádio Coração de Dourados, em 2005, disponibilizados por Elisabete Laet, ela também nos auxiliou na confirmação de informações apresentadas neste texto.

Outra fonte de grande valia foi a obra da professora Maria da Glória Sá Rosa (1990), "Memória da cultura e da educação em Mato Grosso do Sul: Histórias de Vida", que traz a narrativa da história de vida de vários professores que contribuíram para a educação nesse Estado.

Foram estas as principais fontes que possibilitaram a elaboração dos tópicos a seguir. No primeiro, levantamos discursos que contribuíram para construir representações no que tange à implantação e consolidação da instituição escolar Osvaldo Cruz em Dourados nos anos 1960 e, no segundo, enfatizamos as práticas do corpo discente, da referida instituição, apresentadas nas páginas do jornal investigado, como uma luta de representações daquele grupo social.

\section{DISCURSOS E REPRESENTAÇÕES SOBRE O GINÁSIO OSVALDO CRUZ DE DOURADOS: CRIAÇÃO E IMPLANTAÇÃO}

O Ginásio Osvaldo Cruz foi criado em Dourados, em 1954, como uma extensão da Colégio Osvaldo Cruz existente na cidade de Campo Grande, tratando-se da primeira instituição de ensino secundário na cidade de Dourados, que passava por um período de grande expansão demográfica por conta da implantação da Colônia Agrícola Nacional de Dourados (CAND), criada pelo Decreto-Lei n. 5.941, de 28 de outubro de 1943, mas só implantada em 1948, período de governo do presidente Eurico Gaspar Dutra.

O contexto de mudanças a partir da colonização em Dourados e região motivou, em 1950, uma aceleração no desenvolvimento urbano da região, e, entre os feitos, está a extensão do Colégio Osvaldo Cruz de Campo Grande para Dourados. É oportuno salientar que anterior à criação do Ginásio, a escassez de escolas era evidente na cidade, e as poucas existentes não ofertavam ensino secundário. Como é sabido, 
o ensino secundário no Brasil é estruturado a partir das reformas Francisco Campos e Gustavo Capanema durante a Era Vargas, no entanto, ainda nos anos 1950, os estados do interior do país, como Mato Grosso, careciam de instituições com esse nível de ensino.

A Lei Orgânica do Ensino Secundário, de 1942, Decreto-lei n. 4.244, como parte da reforma de Gustavo Capanema, que perdurou até 1961, quando foi promulgada a LDBEN n. 4.024/1961, é conhecida pelo dualismo criado entre o ensino secundário destinado a elite e o profissional para as parcelas menos abastadas da população. A esse respeito, "observa-se que a educação secundária até a década de 1960 tendeu a ser um mecanismo de distinção dentro do contexto social, tendo em vista os parcos investimentos e diversas normatizações que mantiveram seu caráter dualista e seletivo" (BRITEZ, 2014, p. 82). A LDB n. 4.024 de 1961 descentraliza o ensino promovendo uma flexibilização na educação ao inaugurar o chamado técnico-científico, rompendo com o caráter humanista predominante de outrora.

A autora afirma que, no sul de Mato Grosso, a educação secundária "recebeu poucos investimentos do poder estadual [...] com a criação e manutenção de poucas instituições públicas, e privilegiou-se o ensino secundário normal" (BRITEZ, 2014, 101). Rocha (2010, p. 87) corrobora, por sua vez, ao afirmar que "no sul do estado, o poder público não investiu na implantação de estabelecimentos de ensino secundário, o que favoreceu a iniciativa particular a se adiantar e assumir a crescente procura por educação dos estudantes da elite sul-mato-grossense". É nesse contexto que surge o Ginásio Osvaldo Cruz de Dourados, como primeira instituição de ensino secundário na cidade, seguido do Ginásio Presidente Vargas, em 1958, como primeira instituição secundária pública na região ${ }^{10}$.

Sobre os discursos de construção do Colégio Osvaldo Cruz, encontramos dois depoimentos no livro elaborado por Rosa (1990), um de Celso Muller do Amaral, conhecido pelos diversos cargos públicos que assumiu, como vereador e deputado, e o outro pelo professor José Pereira Lins, que tem sua biografia associada ao Ginásio Osvaldo Cruz.

Celso Muller do Amaral afirma que, após ter se formado no curso de Química em 1949, foi convidado pelo reverendo Mário Sydenstricker a abrir, na Escola Erasmo Braga, o curso de admissão no período noturno, para pessoas que almejassem cursar

\footnotetext{
${ }^{10}$ Apesar de ter sido criado pela Lei n. 427, de 2 de outubro de 1951, o Ginásio Presidente Vargas, tinha suas atividades iniciais previstas para 1ㅇ de janeiro de 1955, mas seu primeiro registro de funcionamento data de 15 de fevereiro de 1958 (MARQUES, 2014).
} 
o ginásio. Celso Muller afirma que percebeu a existência de um público brilhante na cidade à época, e a partir "daí surgiu a ideia de implantar-se um ginásio em Dourados". E continua:

Primeiro procuramos os padres salesianos, para que instalassem aqui uma filial do Colégio Dom Bosco mas eles, depois de vir até Dourados, acharam que o lugar não tinha futuro.

Com essa negativa peremptória deles, pensamos no Osvaldo Cruz, de Campo Grande. Conversamos com seu diretor, Dr. Luís Alexandre de Oliveira que aceitou o convite, veio até Dourados para nos visitar e pediu-nos que arranjássemos o prédio, onde o ginásio pudesse funcionar. Éramos um grupo animado, idealista, queríamos ver a cidade crescer. Dele fazia parte o prefeito Nélson Araújo, que conseguiu do Governador Fernando Correa da Costa a cessão de duas salas do Grupo Escolar Joaquim Murtinho, recentemente construído pelo governo do Dr. Fernando.

$[\ldots]$

Assim, em 1954, no atual Grupo Joaquim Murtinho, surgiu nosso primeiro ginásio, o Ginásio Osvaldo Cruz. (AMARAL apud ROSA, 1990, p. 165).

De acordo com o depoimento do professor José Pereira Lins, diretor e proprietário do Ginásio Osvaldo Cruz de Dourados

Em 1954, Dr. Luís Alexandre de Oliveira me convidou para fundar aqui em Dourados um Colégio, junto com o Professor Celso Muller do Amaral. [...] Vim primeiro para os exames de admissão, e, durante dois anos, fiquei indo e vindo ao Ginásio Osvaldo Cruz. [...] vim para Dourados em 1956, depois de adquirir o nome do estabelecimento. O Colégio Osvaldo Cruz tinha a primeira e a segunda séries e era carente de tudo. Funcionava numa das salas do Grupo Escolar Joaquim Murtinho [...] Observei que com o crescimento da cidade a convivência dos dois colégios tornava-se impossível e então aluguei um pardieiro, condenado pela Saúde Pública. Era uma casa de madeira, paredes caindo, galinhas passeando por debaixo do assoalho. Quando alguém se espantava com minhas atitudes, eu respondia que se tratava de um desafio: dar continuidade ao colégio [...] Nesse prédio, fiquei até 1957, quando se formou a primeira turma do Curso Ginasial.

$[\ldots]$

O prédio, o pardieiro a que me referi, pertencia ao Sr. Joaquim de Oliveira, que me alugou por três cruzeiros antigos, o que na época representava substancial ajuda". (LINS apud ROSA, 1990, p. 178).

No entanto "Os exames finais já foram feitos na sede atual, numa chácara de 
dez mil metros, na verdade um terreno sem luz elétrica, cheio de mato, aonde não se chegava nem de charrete" (LINS apud ROSA, 1990, p. 178). Sobre a sede própria, José Pereira Lins menciona que o "prédio do Colégio Osvaldo Cruz, de Dourados, foi idealizado e construído" por um irmão dele (LINS apud ROSA, 1990, p. 176).

Para termos uma dimensão do alcance dessa instituição, verificamos que, no quadro de formandos da primeira turma de ginásio, formaram-se 25 alunos, sendo 11 mulheres e 14 homens. Uma fotografia da inauguração da sede própria do Osvaldo Cruz, datado de 1957, registra cerca de 70 pessoas em traje escolar, configurando os alunos da instituição. Em 1961, segundo consta no jornal O ABC n. 7, p. 3 e 4, o número de estudantes eleitores na 2a Seção Eleitoral no Ginásio Osvaldo Cruz, era de 229 votantes. Em 1960, a instituição passou a ofertar Curso técnico em Contabilidade, em 1965, instalou o Curso Normal.

O segundo número de $O A B C$ (1961a, p. 1) expõe que: “[...] o Ginásio Osvaldo Cruz não é apenas do seu Diretor, é antes de tudo, uma oportunidade apreciável oferecida aos douradenses, e sobretudo um presente à nossa cidade, que muito a engrandece", o que demonstra o esforço por parte do impresso de criar uma representação social de destaque da instituição, na cidade de Dourados, criando um discurso que remete a uma disputa pela consagração institucional no tempo e espaço delimitado.

Como afirma Hernández Díaz (2015, p. 17), os jornais de estudantes secundaristas têm como característica a ênfase e o apreço "à instituição a que pertencem esses estudantes" ${ }^{11}$. Além disso, por tratar-se de uma instituição privada, o Ginásio Osvaldo Cruz de Dourados utilizava-se dos espaços de anúncio do jornal elaborado por seus alunos, para fazer propaganda da instituição, como demonstra a Figura 1.

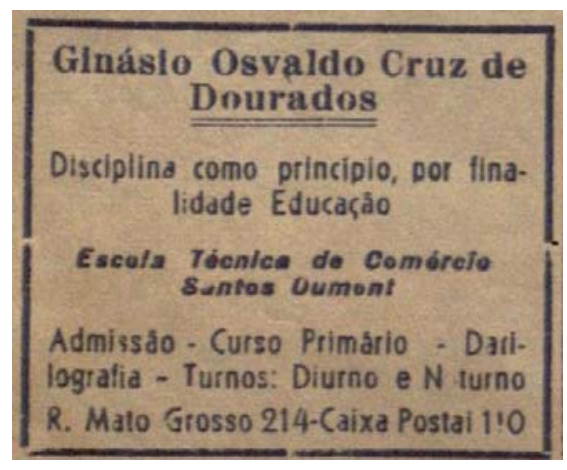

\footnotetext{
${ }^{11}$ Tradução nossa. Versão original: "énfasis y aprecio que se concede a la institución a que pertenecen estos colegiales".
} 
Figura 1 - Propaganda do Colégio Osvaldo Cruz de Dourados, veiculada no Jornal $O A B C$

Fonte: O ABC, 1961c, p. 2

As propagandas referentes ao Osvaldo Cruz aparecem nas páginas de $O A B C$, com esse formato, nos anos 1961 e 1962 (1961 n. 6, p. 2; n. 7, p. 2; 1962, n. 8, p. 2 e n. 10, p. 4). No ano de 1968, o anúncio desaparece, e nenhum outro é apresentado em seu lugar. Contudo, em 1968, diversos artigos são escritos sobre a instituição, produzindo efeito de propaganda, às vezes, ocupando lugar de destaque na primeira página do Jornal ${ }^{12}$, como mencionaremos mais adiante.

O conteúdo do anúncio apresentado na Figura 1 permite algumas observações. A primeira delas é sobre o lema do Ginásio Osvaldo Cruz: "Disciplina como princípio, por finalidade Educação". A frase evidencia um discurso de rigor disciplinar instituído na formação dos alunos. Tal rigor foi mencionado pelo diretor da instituição, em entrevista à rádio Coração no ano de 2005, quando a escola já havia fechado suas portas. Ele afirma que durante sua prática como diretor prezou por uma postura de "muita autoridade e rigidez" em relação aos alunos, segundo ele, pautando-se pelo modelo de educação da época. Mas conclui que, "apesar de todo o rigor" com que tratou os alunos, tudo "foi para o seu bem" (LINS, 2005).

A segunda observação é sobre os períodos de oferta de ensino no Ginásio, que funcionava nos turnos diurno e noturno. Ao que parece, trata-se da primeira instituição a oferecer curso noturno na cidade de Dourados, num período em que a luz elétrica era precária, restrita a locais e períodos do dia. Na mesma entrevista, esta concedida ao jornal Diário MS (2003, p. 5), José Pereira Lins relata o "preconceito" inicial sofrido pela instituição Osvaldo Cruz, que "foi ainda maior quando o colégio passou a oferecer aulas no período noturno, pois as mulheres eram proibidas de estudarem ou saírem à noite". Tal resistência inicial por parte da população traduz-se em relações de força e justifica a necessidade da construção de uma representação positiva da instituição escolar (LINS, 2005).

Outra observação diz respeito aos níveis de ensino oferecidos pela instituição em 1962, que, além do ginásio, contava com o curso primário, o preparatório para o exame de admissão, o curso técnico comercial, e o curso de datilografia. Sobre os cursos e níveis de ensino oferecidos pela Osvaldo Cruz, o Regimento da instituição, de 1970, nessa época denominada Centro Educacional, informa que

${ }^{12}$ Como acontece nos números 1, 2 e 4 de 1968. 
O CENTRO EDUCACIONAL OSVALDO CRUZ DE DOURADOS é o resultado da união das seguintes escolas: Escola Primária Princesa Isabel, Colégio Osvaldo Cruz de Dourados, Colégio Comercial Santos Dumont e Escola Normal Olavo Bilac. (REGIMENTO..., 1970, p. 1).

Essa ampliação do Osvaldo Cruz para a condição de Centro Educacional, aconteceu antes do primeiro semestre de 1968, considerando que, na edição n. 1 de $O$ ABC LITERÁRIO, já constava a nova nomenclatura no corpo do jornal. Nessa edição, o artigo de capa intitulado "Nos currículos da cultura" afirma que o "Centro Educacional Osvaldo Cruz" ministra os cursos: "primário, ginasial, científico, clássico, contabilidade e normal" (ABC LITERÁRIO, 1968a, p. 1). Não localizamos nos periódicos disponíveis o momento em que a instituição passa de Ginásio para Colégio. Nas páginas de $O$ ABC em 1961 e 1962 a nomenclatura adotada era Ginásio e, em 1968, já aparece como Centro Educacional.

Com a existência do Ginásio "Presidente Vargas" na década de 1960, também ofertando o ensino secundário na mesma cidade, o periódico $O A B C$ procurava valorizar sua escola, apresentando-a como um "presente engrandecedor" à cidade. De modo geral, pode-se afirmar que as páginas de $O A B C$ apresentavam a instituição Osvaldo Cruz como o que havia de melhor em termos de instituição secundária, evidenciando as lutas de representações daquele grupo social.

No que diz respeito à distinção entre as duas instituições de ensino ginasial em Dourados, a particular Osvaldo Cruz e a pública denominada Ginásio "Presidente Vargas", o artigo intitulado "Praga ao ensino em Dourados" trata das dificuldades de manutenção do ginásio público. O artigo, sem autoria, afirma: "É, a conclusão a que se chega, observando-se os restos do ex-quase ginásio Estadual Pre. Vargas, o qual, exatamente ao inverso dos outros educandários, não começou pelo berço, mas pelo túmulo" (O ABC, 1962a, p. 1). Enquanto a Osvaldo Cruz é representada como um "presente", que muito orgulha a cidade de Dourados, a "Presidente Vargas" é uma vergonha, impedindo o progresso e a transformação da cidade em metrópole:

É incrível, realmente assombroso, o desapego ao ensino em nossa terra, terra esta que dela tanto necessita, para atingir um grau mais alto de progresso. Como querem dar-lhe o molde de grande metrópole, se sua principal base, esteio de todo país - o ensino - é deixado em último plano, sendo mesmo desprezado, esquecido? Não, não é possível. (O ABC, 1962a, p. 1).

O artigo termina questionando a falta de ação do poder público e da população da cidade, assim como o publicado na edição seguinte, intitulado "Será este o fim?", 
tratando mais uma vez do Ginásio estadual, aquele "que poderia ter sido uma grande fonte de luz do saber para Dourados" mas que estava com os dias contados, "porque antes, apesar de mal acomodados, ainda se estudava no próprio Estabelecimento, atualmente não mais se leciona naquele local, que passou a ser e a representar até um perigo aos que por lá passam" (O ABC, 1962b, p. 1; p. 9). Percebe-se, nesses discursos, ao tratar da não neutralidade, que eles "tendem a autoridade à custa de outras, por elas menosprezadas" (CHARTIER, 1990, p. 17), como estratégia de legitimação da instituição em questão.

Pode-se afirmar, em conformidade com Chartier (1990), que a representação criada e difundida nas páginas do jornal estudantil sobre o Ginásio Osvaldo Cruz de Dourados funciona como força reguladora da vida coletiva impostas por aqueles que detêm o poder de classificar, legitimando valores. Lembrando que se trata de uma instituição de ensino voltada para atender a elite douradense, com certo poder aquisitivo, já que era paga. E os alunos que compunham essa elite contribuíram, por meio do jornal $O A B C$, para que a escola criasse e mantivesse seu status quo.

As festas de inauguração das aulas no Ginásio Osvaldo Cruz e as colunas intituladas "O pátio do Colégio" nas páginas do jornal $O A B C$ reforçam a superioridade dessa instituição em detrimento do Ginásio público. O artigo "A festa do primeiro dia de aula" informa que a comemoração "foi um sucesso. Todos: alegres e animados, divertiam-se a valer. Podem crer, como sempre, a nossa festa estava ÓTIMA!" (O ABC, 1962a, p. 4, grifo no original).

Em 1968, a instituição, agora denominada Centro Educacional Osvaldo Cruz, devia se orgulhar de ex-alunos "espalhados pelas mais diversas Faculdades brasileiras e até mesmo no exterior" (ABC LITERÁRIO, 1968a, p. 1). Outra visibilidade do então Centro Educacional, apresentada pelo jornal estudantil, diz respeito às condições arquitetônicas em constante ampliação e as aquisições pedagógicas.

Sobre as instalações:

O Centro Educacional Osvaldo Cruz continua a largos passos em busca de meIhores dias para a jovem classe estudantil douradense [...] portanto, apesar dos magníficos pavilhões que possui para o ensino, visto o grande número de cursos e constante número de matrículas, seu dirigente encontra-se em necessidade de mais salas para as aulas, o que o levou a iniciação de um projeto para imediata construção de mais um pavilhão com seis salas". (ABC LITERÁRIO, 1968a, p. 1).

Sobre as aquisições pedagógicas, destaca-se o "conjunto anatômico" para o laboratório da instituição: 
Através de ingentes esforços e graças ao dinamismo do Prof. José Pereira Lins, o Centro Educacional Osvaldo Cruz de Dourados acaba de adquirir um moderníssimo Conjunto Anatômico, o mais amplo do Estado, que integrará o patrimônio de pesquisas científicas de nossa cidade. (ABC LITERÁRIO, 1968b, p. 1).

A notícia é apresentada em forma de manchete, ocupando o lugar onde constaria a identificação do jornal, modificando o protocolo de leitura, como uma forma de enfatizar as conquistas da instituição. Como lembra Chartier (1990, p. 17), "não são de forma alguma discursos neutros: produzem estratégias e práticas". Nesse caso, não só a posição em formato destacado é relevante, mas também os dizeres que ocupam as primeiras linhas da capa "Dourados ganha conjunto anatômico: município modelo terá moderníssimo laboratório" (ABC LITERÁRIO, 1968b, p. 1), indicando que a instituição representa o município, assim como a cidade de Dourados é representada pela Osvaldo Cruz, quando se trata de modelo de educação secundária, supervalorizando a instituição.

Por fim, sobre as formas de representação da instituição nas páginas do jornal $O$ $A B C$, destacamos alguns artigos que indicam a preocupação do Ginásio Osvaldo Cruz com a atualidade dos temas apresentados em sala de aula, como o artigo "A Terra Vista do Espaço", que destaca o lançamento do Explorer VII, satélite enviado pelos Estados Unidos da América do Norte, na Califórnia (O ABC, 1962a, p. 3), o "Divórcio no Brasil" (ABC LITERÁRIO, 1968d, p. 1) e a "Pena de Morte" (ABC LITERÁRIO, 1968f, p. 1), os dois últimos, recorrentes e debatidos em sala de aula por meio de um "Júri simulado", como informa a reportagem. Tais matérias, com conteúdos diversos e atuais, se apresentam com o intuito de informar o público leitor, que, pelo que vimos, não se restringia aos alunos da instituição ${ }^{13}$, além de auxiliar na valorização do colégio perante a sociedade douradense.

\section{O COTIDIANO E AS PRÁTICAS ESTUDANTIS NO COLÉGIO OSVALDO CRUZ DE DOURADOS}

Antes de evidenciarmos indícios das práticas estudantis realizadas intra e extra

\footnotetext{
${ }^{13}$ As três primeiras edições de 1968 informam que a tiragem era de 500 exemplares, composto e impresso nas oficinas gráficas de A Folha de Dourados, passando para mil exemplares, impressos no Jornal de Dourados. As edições de 1961 e 1962 não apresentaram o número de exemplares nem como foram impressos. Mas a análise dos anúncios e a forma como eram direcionados, bem como as cartas aos editores, nos permitem afirmar, no que se refere ao público alvo do periódico, que sua divulgação e leitura iam além dos estudantes secundaristas, envolvendo a sociedade douradense como um todo, ultrapassando em alguns momentos os muros da instituição e do próprio município.
} 
muros do Osvaldo Cruz de Dourados, julgamos necessário apresentar mais informações em torno desse periódico, considerando ser "importante estar alerta para os aspectos que envolvem a materialidade dos impressos e seus suportes, que nada têm de natural" (LUCA, 2005, p. 132).

O jornal parece ter sido impresso em seis páginas até o n. 6 de 1961, a partir daí aparece com quatro páginas, sempre em preto e branco e com pouquíssimas edições contendo ilustrações, totalizando quatro figuras nas 12 edições analisadas ${ }^{14}$. Nem as edições especiais em homenagem ao Dia das Mães, no mês de maio, contaram com ilustrações. Nenhuma edição foi impressa em cores. A disposição do texto era apresentada em duas colunas, muitas vezes subdivididas, formando oito colunas por folha, como ilustrado pela Figura 2, na qual apresentamos de forma aleatória uma capa de cada ano do jornal $O A B C$.

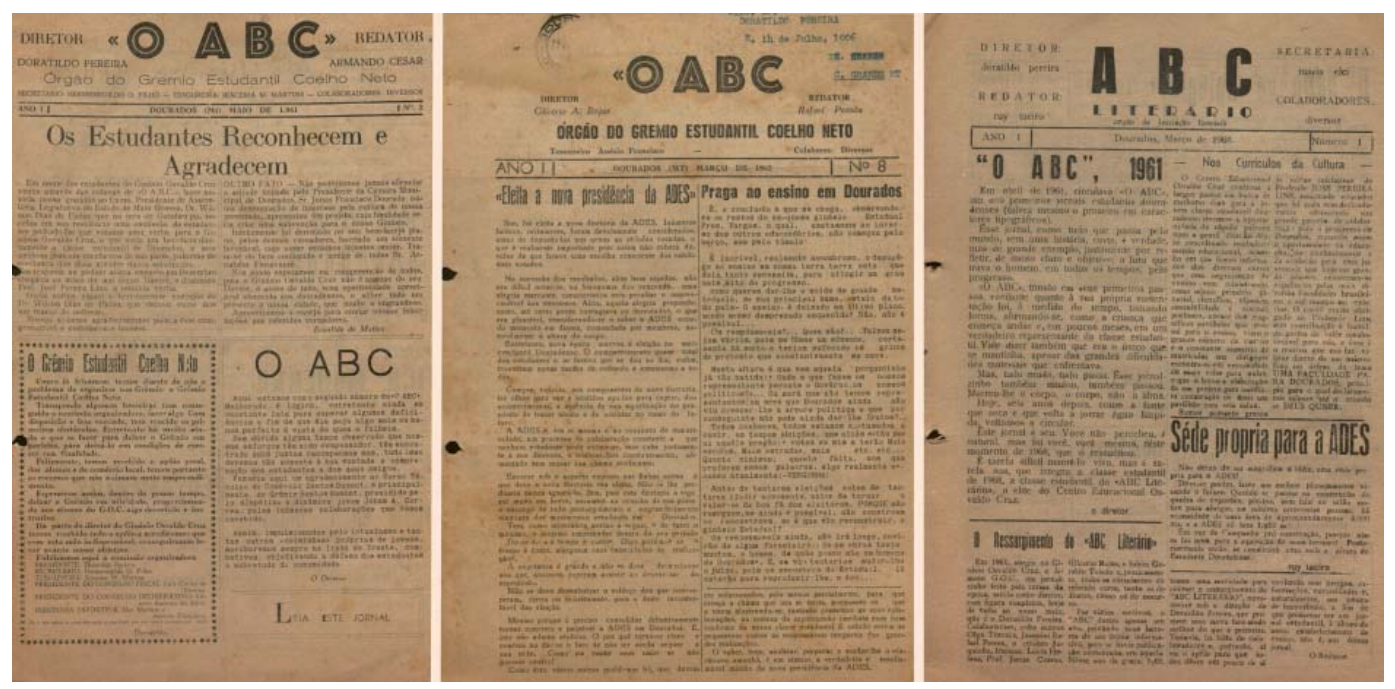

Figura 2 - Primeira folha de exemplares do Jornal O ABC, n. 2 de 1961; n. 8 de 1962 e n. 1 de 1968.

Fonte: CDR/UFGD.

O número de artigos em cada edição variou entre oito e seis. Além dos artigos com temas diversos sobre educação, política e patriotismo, o jornal contava com colunas fixas com espaço para temas do cotidiano dos alunos, mantendo a média

${ }^{14}$ Uma ocorrência de figura para o n. 6 e n. 9 e duas ocorrências no n. 10. 
O Ginásio Osvaldo Cruz de Dourados nas páginas do jornal estudantil ABC: ensino secundário no sul de Mato Grosso nos anos 196

de quatro ou cinco colunas por edição ${ }^{15}$. Os anúncios veiculados nas páginas do jornal giravam em torno de 20 nas primeiras edições (máximo de 25 e mínimo de 19) e a partir do n. 9 baixaram quase pela metade, variando entre 13 e 11 anúncios, presentes em diferentes espaços e tamanhos no jornal. Acreditamos que essa queda no volume de anúncios tenha significado um decréscimo na verba para manutenção do periódico, podendo justificar sua dificuldade de permanência ${ }^{16}$.

Considerando suas condições materiais, rastreamos no jornal estudantil O ABC as práticas e representações sobre o Ginásio Osvaldo Cruz de Dourados, acreditando, conforme Buffa e Nosella (1996), que a imprensa aparece como um novo corpus documental, tão importante quanto às pesquisas ligadas à história das instituições educativas. No entanto, como expõe Dominique Julia, "A história das práticas e culturas é, com efeito, a mais difícil de se reconstruir porque ela não deixa traço" (JULIA, 2001, p. 15).

Ainda assim, acreditamos que $\mathrm{O} A \mathrm{AC}$ apresenta indícios de práticas estudantis realizadas intra e extra muros do Osvaldo Cruz de Dourados, como as festas de início de ano letivo, as narrativas de torneios esportivos, o recorrente piquenique (OABC, 1961c, 1962 ), os júris simulados, os compromissos esportivos em outras cidades, e preparativos para a excursão à Argentina (ABC LITERÁRIO, 1968d, p. 2), bem como os movimentos estudantis e as opiniões políticas dos alunos, como pretendemos demonstrar em seguida. Práticas estas não desprovidas de lutas de poder e de representações sociais.

No que diz respeito à parte recreativa, começamos pelas colunas sobre "mexe-

\footnotetext{
${ }^{15}$ As colunas das primeiras edições eram: "Pimenta", "Mexericos do Pic-Nic", "Sociais", "O ABC nos esportes" e "Pensamentos". A edição n. 6 apresenta as colunas: "Pimenta", "Coluna Social", "Pensamentos", "Página Florida" e "Filme do mês". O n. 7 exclui a coluna "Pensamentos", e os números de 8 a 10 acrescentam a coluna "Bengala Mágica". As edições da nova edição, publicadas em 1968, também variaram suas colunas, intituladas "O Pátio do Colégio", "Pimentinhas", "Sociais" e "Editorial", resgatando nas últimas edições a coluna "Filme do mês".

${ }^{16}$ O jornal estudantil O ABC não apresenta uma nítida relação comercial, considerando que sua distribuição era gratuita, aparentemente sem fins lucrativos, como demonstra a vinheta: "A distribuição deste jornal é gratuita. Colegas, enviem-nos colaborações" (O ABC, 1961b, p. 1). No entanto eram constantes as chamadas sobre colaborações financeiras nas páginas do jornal. "Aceitamos todas e quaisquer colaboração, principalmente financeira" (O ABC, 1961a, dentre outros números). Para manter certa gratuidade, o jornal contava com o patrocínio do comércio local, e em troca disponibilizava espaços para propagandas. São inúmeros e variados os anúncios, sobre autopeças, ótica, cartório, advocacia, engenharia civil, hotel, bar e sorveteria, lojas de artigos, consultório odontológico, entre outros, dando dimensão da organização comercial da cidade.
} 
ricos de cunho amoroso" e "Coisas que merecem destaque", esta última escrita sob o pseudônimo de Garota Solitária, expressando frases desconexas uma das outras, todas, porém, carregadas de sentido, sobre o cotidiano escolar dos alunos do Ginásio Osvaldo Cruz de Dourados, algumas com duplo sentido, outras indecifráveis para "não alunos", como exemplificamos a seguir:

As barrigudas brincadeiras do Lourenço.

A querência de certas garotas pelo Tico.

A beleza da Cleuza com seus penteados que não faz.

A super-elegância da Gizelda.

O namoro da Edna com o '...zinho'.

O aspecto da Jane depois do corte de cabelo.

O noivado da Julita.

O namôro do Gilson com...

O cano que a Izaura levou do Vilmar.

A noivinha Sônia.

A numérica tabuada da Danilda.

O ALIClúme da Edi.

O estudo da Hermantina [ilusão, caprichos etc.].

A graça da Carmélia, a mais bela do GOC.

As confusões dos bilhetinhos.

A ignorância da Maria Lúcia em raiz cúbica. (O ABC, 1962c, p. 4).

A já citada festa do primeiro dia de aula, anunciada como recorrente no Osvaldo Cruz, também pode ser analisada como parte da cultura escolar da referida instituição. "Novamente a festa do início das aulas foi um sucesso". Houve música, prática de esportes (damas, boxe e vôlei feminino). A festa contou com a participação no "salão nobre" da "ADES, GECN, GEPE, EGLP, UNTE e UDCE, todas associações de estudantes locais em conferência" (O ABC, 1962a, p. 4).

Outra prática apresentada como "tradição" entre os alunos do Osvaldo Cruz era o piquenique realizado pelo alunos. Na primeira ocorrência do tema, o evento foi citado em várias partes do jornal. Em nota para agradecer ao senhor Arnulfo Fioravante, por ter cedido sua fazenda para a realização do evento; em artigo com o título "Assim foi o piquenique do dia 8", em que discorria sobre a viagem até o local de encontro, e as atividades desenvolvidas pelos alunos, como nadar, merendar, tirar fotos e se divertir muito até a chegada de uma forte chuva que encerrou o dia de comemorações. Na última página do jornal, uma nota anuncia: "AGUARDEM! Piquenique Monstro", "no próximo dia 6 de maio na fazenda do Sr. Fioravante. Todo aquele que quiser participar deverá adquirir sua passagem que estará a venda a partir 
do dia 25 deste. [...] Preço Cr.\$ 40,00. [...] Obs. Todos pagarão" (O ABC, 1962b, p. 4).

No entanto parece que as atividades recreativas em 1962 já não eram consideradas suficientes pelos movimentos juvenis da época porque, na primeira página do mesmo número do jornal, o artigo intitulado "A respeito do GECN", de autoria de Clicério, sobre o Grêmio Escolar Coelho Neto (GECN), afirma que o grêmio "quase está desaparecendo" porque "os estudantes atuais nada querem com a 'dureza'. Só ligam mesmo para a caderneta de chamada". O autor propõe: "pensemos um pouco na parte esportiva de nossa classe. Façamos algo que torne mais alegre a nossa passagem pelos bancos da escola. Algo que possa ser, mais tarde, lembrado com uma certa alegria". O autor reclama que "desde o ano passado não há mais jogos, festinhas, e outros dêsses movimentos que tanto caracterizam a classe estudantil" (O ABC, 1962b, p. 1).

E, curioso, são justamente por êsses movimentos que nós os estudantes somos geralmente lembrados, mencionados e, por que não, até mesmo admirados? Nós somos, fora de qualquer dúvida, o exemplo vivo da juventude. Devemos pois, não desmerecer essa admiração, e movimentarmo-nos, idearmos e realizar [...] Clicério. (O ABC, 1962b, p. 1).

Ou seja, as atividades recreativas merecem destaque entre as atividades dos alunos secundaristas, afinal, eles são exemplo de juventude. Pelo menos é o discurso que se pretende fazer valer nas páginas do jornal, o de que a juventude é representada não só pela sua formação acadêmica, mas pelas práticas esportivas e de descontração características dessa fase da vida. Como lembra Hernández Díaz (2015, p. 16-17), os jornais feitos por "estudantes adolescentes costumam converter-se em uma oportunidade para plasmar no papel vocações literárias, poéticas ou narrativas", bem como "atividades inovadoras, excursões, prêmios e honras"17.

Em 1968, a chamada para a colaboração de matérias para o jornal, solicitando "artigos, informações, curiosidades, e naturalmente um pouco de humorismo" (ABC LITERÁRIO, 1968a, p. 1), parece manter a filosofia inicial do jornal, que era a de expor as ações que caracterizassem a juventude. E, dada a carência de ilustrações para contribuir nessa empreitada, o humor e ânimo da juventude deveria ser retratado pelo texto escrito.

Outro indício da movimentação criada na cidade pelos alunos secundaristas

\footnotetext{
${ }^{17}$ Tradução nossa. Versão original: "estudiantes adolescentes suele convertirse en una oportunidad para plasmar en el papel vocaciones literarias, poéticas o narrativas [...] actividades novedosas, excursiones, premios y honores.".
} 
é a chamada para que os leitores ouvissem a programação de rádio feita por eles, denominada A Voz dos Estudantes "todo sábado no período da manhã" (O ABC, 1961 a, p. 4). A chamada indica, por sua vez, que os estudantes não se limitavam ao jornal como meio de comunicação e divulgação de suas ideias, procurando abranger todos os meios de expressão em voga naquele contexto, ampliando seus espaços de influência.

Mantendo esse discurso jovial e de valorização das práticas esportivas, os alunos faziam ativas campanhas de arrecadação no jornal escolar, como a "Campanha do Tijolo", para a construção de uma quadra de basquete e futebol de salão para "dotar a cidade de uma quadra oficial" (O ABC, 1961b, p. 1) e a campanha "Sede própria para a ADES" (Associação Douradense dos Estudantes Secundário) (ABC LITERÁRIO, 1968a, p. 1). A chamada era direcionada às autoridades locais e aos douradenses em geral.

No que diz respeito à prática de militância política dos alunos, destacamos o artigo "Os Estudantes Reconhecem e Agradecem", escrito por Eronilde de Mattos, que visa agradecer ao Presidente da Assembleia Legislativa do Estado de Mato Grosso, Wilson Dias de Pinho, que atendeu ao pedido da comissão de estudantes para votar uma verba para o Ginásio Osvaldo Cruz, beneficiando a classe estudantil de Dourados. Outro reconhecimento foi destinado ao Presidente da Câmara Municipal de Dourados, Jonas Francisco Dourado, que, "numa demonstração de interesse pela cultura de nossa juventude, apresentou um projeto, cuja finalidade seria criar uma subvenção para o nosso Ginásio" (O ABC, 1961a, p. 1). Tais práticas demonstram a liderança e a engajamento político de alguns alunos em prol da juventude e da escola, não se restringindo às atividades desportivas ou às funções de aprender o currículo escolar, como querem afirmar.

Eram abrangentes os questionamentos de caráter sociopolítico apresentados pelos alunos nas páginas do jornal $O A B C$, dentre elas, as críticas em relação ao descaso por parte do poder público. Uma crítica, por exemplo, com tom humorístico, refere-se à precariedade das ruas que dão acesso à cidade de Dourados. $\mathrm{O}$ artigo intitulado "Hospital dos Viajantes", afirma que "Projeta-se em Dourados a construção do 'Hospital dos Viajantes', que servirá para atender a todos que chegam de viagem a Dourados", já que o "hospital terá médicos especialistas para recolocação dos órgãos nos devidos lugares, deslocados pela trepidação das estradas e buracos das ruas" (O ABC, 1962c, p. 2).

Algumas críticas, ao que indica nossa análise do jornal, foram repreendidas por autoridades, merecendo, da parte dos alunos um posicionamento. O artigo "Nós 
somos a Pátria", por exemplo, é uma resposta à suposta reclamação dos políticos que foram alvo de críticas.

Muitos há que se incomodam quando através da imprensa se traz ao conhecimento de todos, a revolta que se sente pelo abandono de certos serviços de ordem pública que causam verdadeira vergonha. Querem certamente que se cale diante de todo e qualquer abuso. Porém se somos brasileiros e amamos o Brasil, se vivemos em um Estado e queremos o seu engrandecimento, se pertencemos a um município e almejamos o seu progresso, não podemos silenciar a má vontade dos que têm o poder em suas mãos, culminando em prejuízos à nossa terra e desmoronamento da virtude de nossa gente. [...] aquilo que chamamos de 'CRÍTICA' tem se limitado às verdades mais explícitas, que até uma criança por mais ingênua que seja pode elevar sua voz contra essas injustiças [...] A voz do povo deve ser ouvida. (O ABC, 1962c, p. 1).

Tal discurso ocupa-se em evidenciar que a classe estudantil, pelo menos nos anos iniciais da década de 1960, não pretendia manter-se inerte, estavam ativos em prol do bem dos estudantes, "que formarão o futuro da nação", e assim queriam ser conhecidos. Os movimentos estudantis eram uma constante na década de 1960, não só no Brasil, mas em todo o mundo, tendo como símbolo o "Maio de 1968" na França. O jornal $O A B C$ apresentou uma série de movimentos criados por estudantes, como os do Congresso Estudantil Mato-grossense, sediado em Corumbá, MT, e da Associação Douradense dos Estudantes Secundário (ADES).

Os alunos que escreviam no jornal não apresentavam isenção ou imparcialidade quando se tratava de avaliar ou eleger representantes das associações estudantis existentes. Exemplo disso foi a edição n. 6 de 1961, que apresentou em letras garrafais, antes mesmo do título do jornal, os dizeres: "O problema de reorganização da ADES continua [...]", nele manifestando sua posição contrária à chapa atual e a necessidade de reorganização da Associação (O ABC, 1961b, p. 1). Pode-se dizer, portanto, que $O A B C$ foi um veículo explicitamente político, usado por um grupo de alunos que assumiam a liderança, manipulando as informações e redirecionando, quando julgavam necessário, o protocolo de leitura estabelecido, chamando a atenção para sua posição política.

Na edição do número seguinte, a diretoria do Grêmio Estudantil Coelho Neto lança a candidatura de uma chapa para concorrer à presidência da ADES. Em 1962 $O A B C$ inicia seu primeiro número anunciando "Eleita a nova presidência da ADES". $\mathrm{O}$ artigo parabeniza a chapa vitoriosa, "do momento em diante, comandada por 
membros, naturalmente à altura do cargo" (O ABC, 1962a, p. 1). O jornal não cita o nome da chapa ganhadora, mas pelo tom do discurso deste e de outros artigos relacionados à referida eleição, sua chapa não foi a vencedora.

Um artigo de título "Advertência", escrito por Saul Benedett Maggio, chama atenção dos novos integrantes da diretoria da ADES:

Sempre que uma associação renova sua diretoria, renovam-se também as esperanças de seus associados e simpatizantes. [...] Mas, para que essas esperanças não se transformem em desilusões, se faz necessária uma política estudantil sadia, com princípios construtivos e democrátricos e que a demagogia seja variada dessa associação que tudo significa douradenses. [...] Onde há totalitarismo impera a demagogia. [...] Nós brasileiros temos um exemplo fresquinho de demagogia política - a renúncia do Sr. Presidente da República em 25 de Agosto último: que quase lançôu o Brasil na mais trágica de suas aventuras históricas. Lembra-te estudante, de que uma nação é um todo e, se tu trabalhas para a tua associação, estarás trabalhando para a grandeza do Brasil! (O ABC, 1962a, p. 3).

O tom de importância dado aos movimentos estudantis, de comprometimento com as associações e a forte ideologia pautada no patriotismo, dão a medida da advertência que se pretende direcionar à nova diretoria da ADES.

Em outro artigo chamado "Ponderando", escrito por Adolfo, o autor começa afirmando que o andamento da ADES é animador, após passar por tempos difíceis, resultado de uma má administração. Mas, segundo o artigo, "Agora, sob nova presidência, já conta com o número significativo de quase trezentos sócios", situação contrastante de tempos atrás "não contavam com mais de meia dúzia de elementos". O autor faz menção a evidente expansão da ADES na sociedade douradense, "todos, se não o conhecem, pelo menos ouviram falar".

Temos a sincera conviç̧ão que a 'ADES' não irá ficar no insignificante direito de meia entrada de cinema, ao seu associado. Queremos crer, pois esta nova presidência muito irá realizar ainda, pois até agora nada se fêz, quando após olhar-se o caminho percorrido, voltar-se a contemplar a longa, tão longa estrada à percorrer. Nós, que somos dos extremos, que não aceitamos meios têrmos, ponderamos, apenas ponderamos, e se o snr. Presidente nada fizer quando ao termino de seu mandato, será, unicamente porque assim não quiz, pois, infelizmente, esta é a realidade [...] Adolfo. (O ABC, 1962c, p. 2).

Pelo que pudemos analisar nos discursos dos alunos do Osvaldo Cruz nas páginas do jornal estudantil $O A B C$, além das descontrações, das atividades festivas 
cívicas e sociais e dos romances, eles não deixaram de posicionar-se criticamente em relação aos governantes e às associações de estudantes, o que provavelmente influenciou em seu fechamento, tendo regressado somente em 1968, quatro anos após o início da ditadura militar no Brasil.

Seu retorno em 1968, agora denominado “ABC LITERÁRIO, órgão de iniciação literária", informa no próprio nome, maior suavidade e descomprometimento político, possivelmente para não ser censurado pelas autoridades do regime militar em vigência ${ }^{18}$. Como indica o diretor do jornal em 1968 "O ABC LITERÁRIO é uma nova fase de O ABC, de 1961 (ano de vibração estudantil em Dourados); ABC LITERÁRIO é uma nova época que se pretende fixar; ABC LITERÁRIO é simplesmente um jornal estudantil de 1968 ...!" (ABC LITERÁRIO, 1968a, p. 4).

Para concluir, retomando as manifestações políticas dos estudantes nos dois primeiros anos do jornal, questionamos sobre a atuação feminina nesses engajamentos estudantis partidários, considerando, por exemplo que os artigos a esse respeito foram todos escritos por homens. Retornamos tal questão para destacar que a chapa lançada à candidatura com o apoio do jornal $O A B C$ tinha na direção a figura de uma mulher, o que careceu, por parte do grêmio, de esclarecimentos:

Deve ter causado extranheza o fato de termos apresentado uma moça para presidir a nossa Associação, entretanto é algo natural. Temos na srta Irecema M. Martins, como é do conhecimento de todos, uma pessoa capacitada, de responsabilidade e de espírito empreendedor. (O ABC, 1961c, p. 4).

Tal estranheza pela presença feminina pode ter sido um dos motivos de a chapa, denominada "Progressista", ter perdido as eleições para presidir a ADES, mesmo com o apoio do grêmio e o respaldo do jornal. No entanto há que se considerar que tal prática deve ser avaliada como algo audacioso para a época, considerando, por exemplo, que o próprio jornal $O A B C$ elucida um discurso em que a mulher ocupa papéis específicos, como a edição de colunas que tratam de "mexericos", de moda e de literatura. Por outro lado, constatamos a presença de mulheres, mesmo sendo minoria, tanto na composição da equipe editorial do jornal, quanto na direção dos grêmios que fomentaram essas publicações.

\section{CONSIDERAÇÕES FINAIS}

O impresso estudantil $O A B C$, como principal fonte de pesquisa para esta in-

${ }^{18}$ O Regime militar no Brasil permaneceu entre 1964 e 1985. 
vestigação, permitiu compreender um pouco da trajetória da instituição de ensino secundário Osvaldo Cruz, que nasceu como Ginásio, passando a Centro Educacional, ampliando os níveis de escolarização, e, consequentemente, o número de alunos atendidos por ela, assim como possibilitou uma análise das representações criadas em torno dessa instituição, em Dourados, nos anos 1960, evidenciando as lutas de representações nesse contexto social delimitado.

A ausência de políticas públicas em prol da escolarização, em especial para o ensino secundário, no sul de Mato Grosso, como já evidenciaram outros autores, contribuiu para a implantação da referida instituição. A consolidação da Osvaldo Cruz, por sua vez, contou com os discursos impressos nas páginas do jornal $O A B C$, que criou uma supervalorização dessa escola em detrimento de outras que vieram depois e um vínculo entre ela e o município, como se ela representasse a cidade de Dourados, ora apagando, ora desmerecendo outras instituições educativas.

Os alunos da Osvaldo Cruz evidenciados no jornal estudantil O ABC eram oriundos da classe média e detinham poder de liderança, interferindo na representação da e sobre a cidade de Dourados e da instituição educativa a que representavam, por meio do impresso escolar como veículo de difusão de informações para a sociedade letrada da região. O jornal permite evidenciar as práticas desses estudantes como parte do movimento secundarista da história do movimento estudantil brasileiro na década de 1960.

Esperamos ter cumprido com o intento de (re)escrever um itinerário de vida da instituição escolar Osvaldo Cruz, nos anos 1960, no município de Dourados, ao buscar elucidar as lutas de representações em torno dessa instituição nas páginas do impresso escolar $O A B C$, contribuindo, assim, para a história das instituições educativas e para a história do ensino secundário em Mato Grosso do Sul. Esperamos que este primeiro artigo sirva de incentivo para outras investigações em torno da história dessa e de outras instituições educativas de nível secundário na região.

\section{REFERÊNCIAS}

ABC LITERÁRIO- Órgão de Iniciação Literária do Grêmio Estudantil Osvaldo Cruz. Dourados, MT, n. 1, 1968a.

. Dourados, MT, n. 2, $1968 \mathrm{~b}$.

. Dourados, MT, n. 3, 1968c.

. Dourados, MT, n. 4, 1968d. 
O Ginásio Osvaldo Cruz de Dourados nas páginas do jornal estudantil ABC: ensino secundário no sul de Mato Grosso nos anos 196

. Dourados, MT, n. 6, 1968e.

O ABC- Órgão do Grêmio Estudantil Coelho Neto. Dourados, Mato Grosso, n. 2, 1961a. . Dourados, MT, n. 6, 1961b.

. Dourados, MT, n. 7, 1961c.

. Dourados, MT, n. 8, 1962a.

. Dourados, MT, n. 9, 1962b.

. Dourados, MT, n. 10, 1962c.

BICCAS, Maurilane de S. O impresso como estratégia de formação - revista do ensino de Minas Gerais (1925-1940). Belo Horizonte, MG: Argvmentvm, 2008.

BRITEZ, Adriana Espindola. A representação da educação secundária em Campo Grande nas fontes da historiografia regional e memorialística (1920-1960). 2014. 202f. Dissertação (Mestrado em Educação) - Universidade Federal de Mato Grosso do Sul, Campo Grande, MS, 2014.

BUFFA, Ester; NOSELLA, Paolo. Schola mater: a antiga Escola Normal - 1911-1933. São Carlos, SP: EdUFSCAR, 1996.

CATANI, Denice Bárbara; BASTOS, Maria Helena Camara. Educação em revista: a imprensa periódica e a história da educação. São Paulo: Escrituras, 2002.

CHARTIER, Roger. A história cultural: entre práticas e representações: Bertrand Brasil; 1990.

CRUZ, Heloisa de Faria; PEIXOTO, Maria do Rosário da Cunha. Na oficina do historiador: conversas sobre história e imprensa. Projeto História, São Paulo, n. 35, p. 1-141, dez. 2007.

HERNÁNDEZ DÍAZ, José María (Org.). La prensa pedagógica de los escolares y estudantes: su contribuición al património histórico educativo. Salamanca, ES: Ediciones Universidad de Salamanca, 2015.

HERNÁNDEZ DíAZ, José María. Prensa pedagógica e patrimônio histórico educativo. Salamanca-ES: Ediciones Universidad de Salamanca, 2013.

JULIA, Dominique. A cultura escolar como objeto histórico. Revista Brasileira de História da Educação, São Paulo, n. 1, jan./jun. 2001.

LINS, José Pereira. Entrevista concedida à Rádio Coração, como parte do projeto "Memória", 2005. [áudio].

LUCA, Tânia Regina de. História dos, nos e por meio dos periódicos. In: PINSK, Carla Bassanezi. Fontes Históricas. São Paulo: Contexto, 2005.

MAGALHÃES, Justino Pereira de. Tecendo nexos: história das instituições educativas. Bragança Paulista,SP: Editora Universitária São Francisco, 2004. . Contribuindo para a história das instituições educativas - entre a Memória e o 
Arquivo. Braga: Universidade do Minho, 1996.

MARQUES, Inês Velter. O ensino secundário no sul do antigo Mato Grosso: o Colégio Estadual Presidente Vargas de Dourados (1951-1974). 2014. 134f. Dissertação (Mestrado em Educação) - Universidade Federal da Grande Dourados, Dourados, MS, 2014.

REGIMENTO interno do Centro Educacional Osvaldo Cruz. Dourados, Mato Grosso, 1970. ROCHA, Marcelo Pereira. O ensino secundário no sul do estado de Mato Grosso no contexto das reformas educacionais: o Ginásio Osvaldo Cruz (1927-1949). 2010. 97f. Dissertação (Mestrado em Educação)- Universidade Católica Dom Bosco, Campo Grande, MS, 2010.

ROSA, Maria da Glória Sá. Memória da cultura e da educação em Mato Grosso do Sul. Campo Grande: Editora da UFMS, 1990.

ZOTTI, Solange Aparecida. O currículo do ensino secundário e a formação das elites republicanas. In: SIMPÓSIO NACIONAL DE HISTÓRIA- História: Guerra e Paz, 23., 17-22 jul. 2005. Anais... Londrina: Editorial Mídia, 2005.

\section{Sobre as autoras:}

Kênia Hilda Moreira: Doutora em Educação Escolar. Professora no Programa de Pós-Graduação em Educação e na Faculdade de Educação da Universidade Federal da Grande Dourados. E-mail: keniahildamoreira@yahoo.com.br

Eglem Oliveira Passone Rodrigues: Mestranda do Programa de Pós-Graduação em Educação, na Faculdade de Educação da Universidade Federal da Grande Dourados. E-mail: eglempassone@gmail.com

\section{Recebido em setembro de 2016}

\section{Aprovado para publicação em julho de 2017}

